\title{
Educating Aerospace Design Engineers: Perspectives from Design Creativity Theory
}

\author{
Suo Tan ${ }^{a}$, Catharine Marsden ${ }^{b^{*}}$ and Yong Zeng ${ }^{a}$ \\ ${ }^{a}$ Concordia Institute for Information Systems Engineering, \\ Faculty of Engineering and Computer Science, Concordia University \\ ${ }^{b}$ Centre for Engineering in Society, \\ Faculty of Engineering and Computer Science, Concordia University \\ *Corresponding Author. E-mail c.marsden@concordia.ca
}

\begin{abstract}
When seeking candidates for engineering design positions, aerospace companies usually seek to hire high qualified professionals while overlooking recent graduates from engineering schools. The reason for this is the opinion that most of the engineers graduating from universities do not possess the skill sets the companies are seeking and that it takes too long to train recent graduates in the complexities of the aerospace design process. There is a need to minimize the gap between the needs of the aerospace industry and the training of engineers at the university level and this need cannot be met without the collaboration of aerospace firms, universities and government. In this paper, we propose an approach to educating undergraduate aerospace engineering students based on design creativity theory. The NSERC Chair in Aerospace Design Engineering (NCADE) at Concordia University will be used as a test bed to implement, validate, improve and promote this educational strategy.
\end{abstract}

Keywords: Educating engineers, aerospace design, design creativity theory, NCADE.

\section{INTRODUCTION}

There exists a well-documented disconnect between the needs of the aerospace industry and the training of undergraduate engineers at the university level [1,2]. This gap is not unique to the aerospace industry [3] or to the North American context [4]. It is widely acknowledged that the next generation of aerospace engineers must be knowledgeable and creative; they must be ready to contribute technically to the design and development of innovative products and processes; they must adapt to rapidly-evolving technologies, and must possess the professional and personal attributes required to form effective partnerships within multi-disciplinary teams and in multi-cultural working environments.

A high level of agreement exists within the aerospace community as to the core competencies and skills that should be acquired during an undergraduate engineering education in order to provide the industry with design engineers possessing the desired balance between practice and theory, and personal and interpersonal professional skills $[6,7]$. Despite a number of outstanding programs at well-known institutions $[3,12]$, the dissatisfaction felt by the aerospace industry with the design engineering content of our undergraduate engineering programs is still evident. It is thus an urgent task for design education to contribute directly to solving this problem through changes to curriculum, teaching and learning strategies, assessment, research, evaluation and continuous improvement. To this end, the first task is to lay out the competencies needed for an aerospace engineer.

As we understand more about the skills that our undergraduate engineering programs need to develop in our students, we are faced with the increasingly challenging task of how to provide these students with the opportunities they require to develop those skills within the scope of an undergraduate engineering program. Engineering curricular requirements have been changed to increase design content and to include courses with a focus on professional skills such as technical writing, legal and ethical considerations and the environmental impacts of engineering decisions. In addition to studying the fundamental engineering sciences, students are expected to keep up to speed with rapidly advancing technologies in computer modeling and analytical software packages. In addition, we would like to offer them more opportunities to develop personal and professional skills such as teamwork, entrepreneurship, life-long learning, presentation and listening skills, global awareness, business practices, decision making, critical thinking, dealing with uncertainty and creativity. We would also like to meet these needs without decreasing the student's exposure to fundamental engineering sciences and without increasing the course load within the scope of existing degree programs. The NCADE program at Concordia University is designed to address this challenge through changes to the way the curriculum is delivered and adopts

CEEA16; Paper 140

Dalhousie University; June 19 - 22, 2016 
a "three-pillared" approach based on (i) implementing novel teaching and learning strategies aligned with a new aerospace engineering curriculum; (ii) offering students opportunities to gain practical, hands-on experience through internships and apprenticeships and; (iii) increasing experiential learning through project-based content, capstone course design and implementation and increased laboratory experiences.

\section{DESIGN CREATIVITY THEORY}

Nguyen and Zeng (2012) have proposed a theoretical model of design creativity which uses the EnvironmentBased Design [4,5] as a general design process model and includes the following postulates:

- Postulate 1: Design reasoning follows a nonlinear dynamic, which may become chaotic.

- Postulate 2: Design creativity is related to a designer's mental stress through an inverse U shaped curve (see Fig. 1).

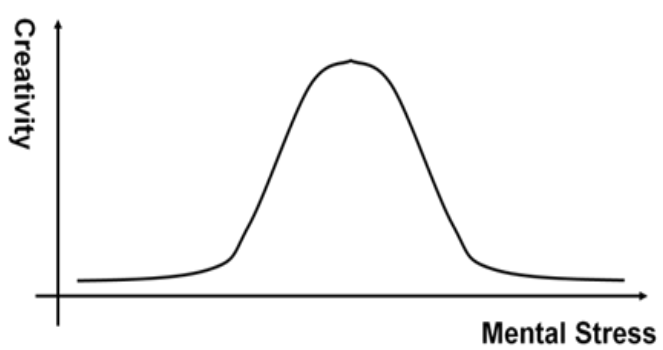

Fig. 1. Inverse $U$ curve relation between mental stress and design creativity (Nguyen \& Zeng, 2012).

The first postulate describes design as a nonlinear dynamical process where the outcome is sensitive to the initial conditions and addresses the relationship between evolving design states. A small change in the initial design state may lead to diverging states of design outcomes. Designing is formulated as an environment evolutionary process where an earlier design solution becomes a part of the environment for the current design stage. This environment evolution implies a nonlinear chaotic dynamic, in which the design problem, design solution, and design knowledge will change in a recursive and interdependent manner $[1,2]$. This postulate depicts the nondeterministic and unpredictable nature of design creativity and captures the recursive interdependence between design problem, design solutions, and design knowledge, all of which evolve simultaneously in the design process. A great deal of uncertainty is inherent in this nonlinear recursive design process, which may lead to mental stress on designers.

The second postulate states that design creativity is at a maximum when a designer is under a medium level of mental stress as shown in Figure 1, which is adapted from the well-known Yerkes-Dodson law [3]. Mental stresses are positively related to the workload associated with a design problem and negatively related to the designer's mental capacity. The workload is related to the complexity of the design problem and the amount of work in the design process whereas the mental capacity is related to the knowledge and skills required by the design process and to the designer's emotional state when dealing with the stresses arising from uncertainties and unpredictability of the design dynamics. The mental stress, workload (task demand) and mental capacity can be associated with each other using the following equations:

$$
\begin{gathered}
\text { mental stress }=\frac{\text { Workload }}{\text { Mental Capability }} \\
=\frac{\text { workload }}{(\text { knowledge }+ \text { skills }) * \text { affect }} \\
\text { affect } \in[0,1]
\end{gathered}
$$

Where the parameters are defined as:

- $\quad$ Knowledge (denoted by K): structure of knowledge. This depends on how the knowledge is structured and organized for efficient storage and retrieval.

- Skills (denoted by $S$ ): refers to thinking styles, reasoning methods and thinking strategy.

- $\quad$ Affect (takes a value from 0 to 1 and is denoted by $A)$ : refers to a person's emotional state or mood and is determined by personality, attitude, belief, motivation, and availability of cognitive resources.

- $\quad$ Perceived workload (denoted by $W^{P}$ ): refers to a temporal manifestation of the real workload (denoted by $W^{L}$ ) and is determined by perception.

The amount of external workload is the most direct source of mental stress. A greater workload may trigger a greater mental stress. This workload can be associated with the complexity of the problem. Moreover, it is not uncommon that the same workload may trigger different mental stresses on different individuals and the same workload may trigger different mental stresses for the same individual under different circumstances. This theory has been being tested in a series of physiological experiments $[4,5]$.

In the context of aerospace engineering design training, the creativity in Figure 1 may be interpreted as the students' effectiveness in tackling a design problem. The mental workload is a combination of the technical knowledge associated with aerospace design and the knowledge of the design process itself that we wish the students to acquire. The students' current status of knowledge, skills, attributes and associated emotional state 
or "affect" will determine their level of stress and subsequent efficiency and effectiveness in undertaking the design process.

In the next section, we will look at what are considered core competencies for the aerospace design engineer from these three aspects of knowledge, skills and affect.

\section{AEROSPACE DESIGN CORE COMPETENCIES}

A study of cross-disciplinary engineering programs [6] concluded that the most important of the engineering competencies listed by the American Accreditation Board for Engineering and Technology (ABET) are the ability to work on a team, written and oral communication skills, engineering problem-solving skills, and the ability to analyze and interpret data. This was closely followed by the ability to continue formal or informal learning, the understanding of professional and ethical responsibility, math, science and engineering skills, the ability to design a system, component or process and the ability to use modern engineering techniques, skills and tools.

In the aerospace sector, the Boeing Corporation has developed a list of desired traits and attributes of a graduating engineer [7] that includes engineering science fundamentals, an understanding of design and manufacturing processes, a multi-disciplinary systems perspective, an understanding of the context in which engineering is practiced, communication skills, high ethical standards, an ability to think both critically and creatively - independently and cooperatively, the ability and self-confidence to adapt to rapid or major change, curiosity and a desire to learn for life, and a profound understanding of the importance of teamwork. Boeing CEO Phil Condit summarized the desired attributes of an aerospace engineer as collaboration, communication, cost awareness and continuous learning [7]. More specifically in the aerospace design context, Nicolai and Schrock [10] provided the desired skills of an aerospace design engineer for the Lockheed Martin Aeronautics Company as listed in Table 1.

Table 1. Desired skills for an Aerospace Aircraft Design Engineer (adapted from [10])

\footnotetext{
- Analyzing requirements

- Developing a strategy to address the requirements

- Executing initial sizing and developing preliminary sketches

- Making tough decisions among different configuration choices

- Substantiating the choices with engineering analysis

- Developing configuration drawings

Executing vehicle sizing to constraints

Performing trade studies

Making design decisions and executing them

Documenting and finalizing the design concept
}

In this paper, we will consider these desired skills and attributes as put forward by the aerospace industry in the context of design creativity theory as "knowledge", "skills", and "affects", respectively. The NCADE program at Concordia University includes the development and implementation of an undergraduate apprenticeship program and a final year Aircraft Design Project, both intended to increase the students' opportunity to acquire critical technical and professional skills. The purpose of restructuring the desired skills and attributes in the design creativity context is a first step in applying the theory to design these aspects of the program so that they can be most effective in training the next generation of aerospace engineering designers.

\subsection{Aerospace design knowledge}

In the context of design creativity theory, the structure of design knowledge depends on how the knowledge is structured and organized for efficient storage and retrieval. This is aligned with the desired attributes of engineering science fundamentals, an understanding of design and manufacturing processes, a multi-disciplinary systems perspective and an understanding of the context in which engineering is practiced. Aerospace design is an extremely complex, iterative, system-of-systems, challenging environment with an extremely cross-disciplinary and multi-technology design space. The design tasks are accomplished in a highly-regulated environment where design requirements can change rapidly and abruptly in response to a highly competitive marketplace. The product is high-value and design is heavily driven by cost and timeto-market considerations.

When facing the aerospace design problem, novice designers can be overwhelmed by the huge amount of information and options available [9], especially for the illdefined, open-ended design problem that is aircraft conceptual and preliminary design. The ideal aerospace design engineer understands the requirements of both the manufacturer, the operator and the end user, the physical and regulatory environment in which the product is expected to operate, the technological design constraints resulting from performance, reliability and certification requirements and the cost and schedule constraints that can drive a design program.

The NCADE program aims to increase students' exposure to aerospace design knowledge by including industry engineers as adjunct professors and co-teachers for product relevant knowledge transfer, by integrating coursework across disciplines to enhance multidisciplinary training, by implementing a coherent design education evolution intended to maximize the students' learning process at each stage in the acquisition of their skills and competencies and including opportunities for self-learning and peer-teaching meant to enhance the desired professional skills. 


\subsection{Aerospace design affect}

Affect, in this context, is related to the emotional state of a designer involved intensively in designing an aerospace product. Affect refers to an emotional state, and is also determined by personality, attitude, belief, motive and stress. Affect can determine how much of one's knowledge and skills can be effectively used in solving the problems associated with complex designs. A designer's mental capacity can be defined by his/her knowledge and skills, and a lack of skills and knowledge may increase mental stress. Furthermore, a large amount of uncertainty and unpredictability exists in the aerospace design group due to the challenging and iterative nature of the task. This uncertainty may be transformed to mental stress in the form of emotion based on the designer's ability to work with unpredictability and uncertainty. The uncertainty may trigger negative feelings such as frustration and fear of failure which can, in turn, determine how effectively the designers' knowledge and skills can be implemented during the design process.

The NCADE program, with its focus on coherent design education evolution, multi-disciplinary training environment and final year group design project, is being designed to develop the students' mental capacity over the four years of their engineering degree. It is intended that students will tackle increasingly challenging design tasks in larger and more cross-disciplinary groups as they progress through their degree program. This is aligned with the opportunity to practice and evolve desired skills and attributes such as communication skills, the ability to think both critically and creatively - independently and cooperatively, the ability and self-confidence to adapt to rapid or major change, curiosity and a desire to learn for life, and a profound understanding of the importance of teamwork. It is planned that students' mental model in learning aerospace design at different stages will be assessed by cognitive research systems: EEG systems, eyetracking system, video surveillance systems and physiological sensors to measure HRV, GSR, and respiration rate. As a result, we will be able to monitor students' mental status and affect at each learning stage, and adjust the program to maximize the learning and skills acquisition of the student.

\subsection{Aerospace design skills}

In the context of design creativity theory, skills refer to thinking styles, reasoning methods and thinking strategies. These are aligned with the aerospace industry desired attributes such as analyzing requirements, developing strategies to address requirements, performing trade studies, making design decisions and selecting among different configuration choices, multi-disciplinary systems perspectives and a good understanding of manufacturing and design processes, among others. In the context of aerospace engineering design training, the mental workload is the aerospace design knowledge and process. As long as the workload related sub-problem is within the scope of a designer's expertise, the designer can perceive the workload correctly and his mental stress will fall into the optimal/near optimal zone.

The NCADE program is being designed to first teach students design reasoning, design thinking and decision making strategies and processes early in their engineering education and then allow them to apply and practice those methods and strategies in multiple and increasingly complex design experiences over the course of their engineering education by applying the theory of design creativity to enhance students design performance in an evolutionary manner.

The theoretical model of design creativity can also be used to define the relationship between mental stress and performance by replacing creativity with performance. The translation from actual workload, $W^{L}$, to perceived workload, $W^{P}$, is illustrated in Figure 2. During the perception process, the knowledge, skills and affect being used $\left(K^{P}, S^{P}\right.$ and $\left.A^{P}\right)$ will work together on the assigned workload, $W^{L}$, and will result in a perceived workload, $W^{P}$, on the part of the student designer. $K^{P}, S^{P}$ and $A^{P}$ are the portion of the total available knowledge, skills and affect $\left(K^{L}, S^{L}\right.$ and $\left.A^{L}\right)$, respectively, that the student designer can access at any point in his/her training.

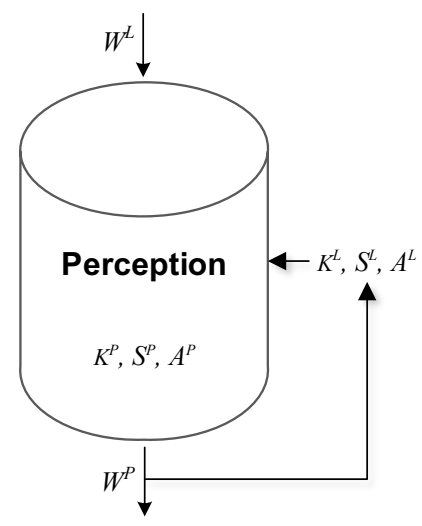

Fig. 2. Workload is the manifest of perception.

Increasing perceived workload leads to increased mental stress and can result in decreased performance as shown in Figure 3. In the case of the aerospace engineer in training, the increasing perceived or mental workload can impact the students' ability to acquire and develop new design skills. Since the aerospace design project is a topdown and ever-evolving process, at each design stage the design statement and requirements will change and will involve new concepts, knowledge and tools. As the design process evolves the overall workload will significantly increase. 


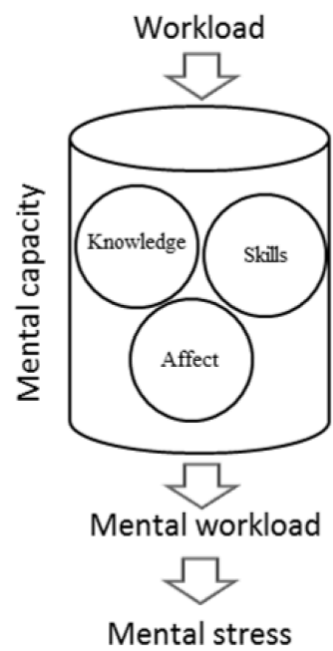

Fig. 3. Mental stress is positively related to workload and negatively related to mental capacity.

The NCADE program will adopt the "divide-and-conquer" or decomposing technique to help students with differing skill levels solve problems by recursively breaking them into smaller sub-problems until the sub-problem becomes solvable. The simpler sub-problems can then be solved and the results combined to provide a solution to the larger problem. This is an approach that can be used to develop the design projects the students will be working on. When an engineering student faces a smaller problem that is within the scope of his or her knowledge and skills, the perceived workload will be much less than when facing a large problem for which their knowledge and skills are not ready. The decomposing skill is also a strategy that the students will learn and will be one of their key skills that, once mastered, will help them maintain an optimal stress level in the face of complex and difficult design problems.

\section{CONCLUSIONS AND DISCUSSION}

The method used to classify, formulate, and represent the various kinds of information involved in a design problem is essential for modeling and improving design practices. The design creativity theory, founded in Environment-Based Design, proposes a general design process model including the postulate that design reasoning follows a nonlinear dynamic, and that design creativity is related to a designer's mental stress through an inverse U shaped curve.

It is proposed to implement elements of this design process model in developing and implementing curriculum and program changes in the context of the NSERC Chair in Aerospace Design Engineering (NCADE) at Concordia
University. Design is not a linear process and iterates between problem definition, design knowledge acquisition, application and multiple interim design solutions. A reallife design problem rarely contains all the information necessary to solve it, making it necessary to adopt recursive strategies to arrive at a satisfactory solution.

The aerospace design problem is a complex and challenging example of this process, and, as a result, can be difficult to teach in the university environment. The aerospace industry has identified a number of skills and attributes that it would like to see improved for future engineering graduates. In this paper, these skills and attributes, as identified by members of the aerospace design community, have been restructured and expressed in terms of design creativity theory. The knowledge, skills and affect elements that contribute to a designers' mental capacity can be combined with workload definition to evaluate the designer's mental stress and then to his/her level of creativity and/or performance. When applied to the problem of designing curriculum to optimize the training of aerospace design engineers, the reformulated skills and attributes relate directly to the knowledge, skills and affects of the design creativity theory, providing a model for design education and strategies for curriculum development.

\section{ACKNOWLEDGEMENT}

The research presented in this paper is financially supported by the NSERC Chair in Aerospace Design Engineering (NCADE) program.

\section{REFERENCES}

[1] Y. Zeng, and G. D. Cheng (1991), "On the logic of design,” Design Studies, vol. 12, no. 3, pp. 137 141

[2] Y. Zeng, and P. Gu (1999), "A science-based approach to product design theory Part I: formulation and formalization of design process," Robotics and Computer-Integrated Manufacturing, vol. 15, no. 4, pp. 331-339

[3] R. M. Yerkes, and J. D. Dodson (1908), "The relation of strength of stimulus to rapidity of habit-formation," Journal of Comparative Neurology and Psychology, vol. 18, no. 5, pp. 459-482

[4] T. A. Nguyen, and Y. Zeng (2016), "Effects of stress and effort on self-rated reports in experimental study of design activities," Journal of Intelligent Manufacturing, pp. 1-14

[5] T. A. Nguyen, and Zeng (2014), "A physiological study of relationship between designer's mental effort and mental stress during conceptual design," Computer Aided Design, vol. 54. pp

[6] H. J. Passow (2012), "Which ABET competencies do engineering graduates find most 
important in their work?," Journal of Engineering Education, vol. 101, no. 1, pp. 95-118

[7] R. M. Goff, and J. P. Terpenny (2012), "Engineering Design Education - Core Competencies." 50th AIAA Aerospace Sciences Meeting, No. AIAA 2012-1222, Nashville, TN, 09-12 January 2012.

[8] I. Markes (2006), "A review of literature on employability skill needs in engineering," European Journal of Engineering Education, vol. 31, no. 6, pp. 637-650

[9] S. Ahmed, and K. M. Wallace (2004), "Understanding the knowledge needs of novice designers in the aerospace industry," Design Studies, vol. 25, no. 2, pp. 155-173

[10] Nicolai, L. and Schrock, E. (2010), "What Would Industry Like To See Covered In The Senior Capstone Design Course," 10th AIAA Aviation Technology, Integration, and Operations (ATIO) Conference, No. AIAA 2010-9014, Fort Worth, TX, 13-15 September 2010 